DOI 10. 18307/2019. 0508

(C) 2019 by Journal of Lake Sciences

\title{
云南程海浮游植物初级生产力的时空变化及其影响因子"
}

\author{
黄立成 ${ }^{1}$, 周远洋 ${ }^{1,2}$, 周起超 ${ }^{1,3 * *}$, 王玮珞 ${ }^{1}$, 董云仙 ${ }^{1}$, 李凯迪 ${ }^{1,2}$, 常军军 ${ }^{2 * *}$ \\ (1: 云南省环境科学研究院云南省高原湖泊流域污染过程与管理重点实验室, 昆明 650034) \\ (2:云南大学生态学与环境学院, 昆明 650500) \\ (3:云南大学资源环境与地球科学学院/高原湖泊生态与治理研究院, 昆明 650500)
}

\begin{abstract}
摘 要: 2016 年 4 月- 2017 年 2 月, 采用黑白瓶法研究了云南程海单点 (码头点位) 浮游植物初级生产力的垂直分布及 其季节变化, 同时基于全湖 9 个点位的现场调查和生产力垂向归纳模型 (VGPM) 估算并探讨了程海浮游植物初级生产力 的时空变化及其主要影响因子. 结果显示, 码头点位的年均 (均值土标准误) 水柱 $(0 \sim 3 \mathrm{~m})$ 总初级生产力 $\left(\mathrm{GPP}_{\mathrm{C}}\right)$ 、净初级 生产力 $\left(\mathrm{NPP}_{\mathrm{C}}\right)$ 和呼吸消耗量 $\left(\mathrm{R}_{\mathrm{C}}\right)$ 分别为 $5.40 \times 10^{3} \pm 0.64 \times 10^{3} 、 2.36 \times 10^{3} \pm 0.63 \times 10^{3}$ 和 $3.06 \times 10^{3} \pm 0.82 \times 10^{3} \mathrm{mg} \mathrm{O}_{2} /\left(\mathrm{m}^{2}\right.$. d) ; 不论春夏季 $(4-8$ 月)、秋冬季 ( 9 月一次年 2 月) 还是全年, 码头点位的单位生物量 GPP (GPP/Chl.a) 和单位生物量 $\mathrm{NPP}$ (NPP/Chl.a) 的最大值和最小值均分别出现在水下 $0.5 \mathrm{~m}$ 和 $3.0 \mathrm{~m}$ 处. 经 VPGM 估算, 程海全湖的初级生产力 $\left(P P_{\mathrm{eu}}\right)$ 年均值为 $6.54 \times 10^{3} \pm 0.30 \times 10^{3} \mathrm{mg} \mathrm{C} /\left(\mathrm{m}^{2} \cdot \mathrm{d}\right)\left(2.74 \times 10^{3} \sim 18.62 \times 10^{3} \mathrm{mg} \mathrm{C} /\left(\mathrm{m}^{2} \cdot \mathrm{d}\right)\right) . P P_{\mathrm{eu}}$ 的时空变化方面, 春夏季是 $P P_{\mathrm{eu}}$ 快速上升的时节, 秋冬季 $P P_{\mathrm{eu}}$ 的月变化则呈波动状态, 春夏季与秋冬季 $P P_{\mathrm{eu}}$ 无显著性差异; $P P_{\mathrm{eu}}$ 整体空间异质性较弱, 仅 在降水最为充沛的 7、8 月表现出南北向的异质性, 这与降水条件和流域营养盐输人的空间异质性有关. 回归分析发现, 虽 然程海 $P P_{\mathrm{eu}}$ 的主要影响因子具有季节异质性, 但不论春夏季、秋冬季还是全年, 浮游植物生物量均是重要的影响因子, 水 温亦是春夏季的重要影响因子.
\end{abstract}

关键词: 浮游植物初级生产力; 黑白瓶法;生产力垂向归纳模型;时空分布;程海

\section{Temporal-spatial variation in phytoplankton primary production and its influencing factors in Lake Chenghai on the Yunnan Plateau, China}

HUANG Licheng $^{1}$, ZHOU Yuanyang ${ }^{1,2}$, ZHOU Qichao ${ }^{1,3 * *}$, WANG Weilu ${ }^{1}$, DONG Yunxian ${ }^{1}$, LI Kaidi ${ }^{1,2}$ \& CHANG Junjun ${ }^{2 * *}$

(1: Yunnan Key Laboratory of Pollution Process and Management of Plateau Lake-Watershed, Yunnan Institute of Environmental Science, Kunming 650034, P.R.China)

(2: School of Ecology and Environmental Science, Yunnan University, Kunming 650500, P.R.China)

(3: Institute for Ecological Research and Pollution Control of Plateau Lakes, School of Resource Environment and Earth Science, Yunnan University, Kunming 650500, P.R.China)

Abstract: From April 2016 to February 2017, the temporal-spatial distribution of phytoplankton primary production in Lake Chenghai at Yunnan, China was investigated monthly via light-dark bottle method (at a dock site) and vertically generalized production model (VGPM) (across nine sampling sites), and the potential influencing factors were also analyzed. The results showed that the annual mean values $($ mean $\pm \mathrm{SE})$ of gross primary production $\left(\mathrm{GPP}_{\mathrm{C}}\right)$, net primary production $\left(\mathrm{NPP}_{\mathrm{C}}\right)$ and respiration $\left(\mathrm{R}_{\mathrm{C}}\right)$ of water column $(0-3 \mathrm{~m})$ at dock site were $5.40 \times 10^{3} \pm 0.64 \times 10^{3}, 2.36 \times 10^{3} \pm 0.63 \times 10^{3}$ and $3.06 \times 10^{3} \pm 0.82 \times 10^{3} \mathrm{mg} \mathrm{O}_{2} /$ $\left(\mathrm{m}^{2} \cdot \mathrm{d}\right)$, respectively. Meanwhile, the maximal and minimal values of the GPP and NPP per biomass (GPP/Chl.a and NPP/Chl.a) in vertical profile were both present at the depth of $0.5 \mathrm{~m}$ and $3.0 \mathrm{~m}$ respectively, whether during spring and summer (from April to

* 国家自然科学基金项目(41601208)、国家重点研发计划项目(2017YFA0605202)、云南省环保专项项目和云南省环境 科学研究院创新团队计划项目联合资助. 2019-01-27 收稿;2019-02-28 收修改稿. 黄立成 (1990 ), 男, 硕士, 助理 工程师;E-mail: faithhlc@163.com.

** 通信作者;E-mail: qchzhou@ynu.edu.cn, changjunjun@ynu.edu.cn. 
August, 2016), autumn and winter (from September 2016 to February 2017) or the entire experimental period at dock site. Moreover, the annual mean value and range of the phytoplankton primary production $\left(P P_{\mathrm{eu}}\right)$ estimated by VGPM were $6.54 \times 10^{3} \pm$ $0.30 \times 10^{3}$ and $2.74 \times 10^{3}-18.62 \times 10^{3} \mathrm{mg} \mathrm{C} /\left(\mathrm{m}^{2} \cdot \mathrm{d}\right)$, respectively. $P P_{\text {eu }}$ increased rapidly during spring and summer, and fluctuated during autumn and winter. No significant difference for $P P_{\text {eu }}$ was detected between spring-summer and autumn-winter. The spatial heterogeneity of $P P_{\text {eu }}$ was weak in general despite the significant difference in the north-south direction in July and August with plentiful rainfall which might be related to the rainfall and spatial heterogeneity of nutrients input from the basin. Furthermore, although the major influencing factors for $P P_{\mathrm{eu}}$ and their relative importance were changed with season, the phytoplankton biomass was the most important factor impacting $P P_{\text {eu }}$ during the entire period, and the water temperature was also an important factor during spring and summer.

Keywords: Phytoplankton primary production; light-dark bottle method; vertically generalized production model (VGPM) ; temporal-spatial distribution; Lake Chenghai

初级生产力是自养生物利用太阳能进行光合作用 (或利用化学能进行化能合成作用) 同化无机碳为有 机碳的能力. 浮游植物通过光合作用积累的物质及储存的能量是湖泊生态系统物质循环和能量流动以及食 物网和渔业生产的基础; 浮游植物贡献的初级生产力约占生物圈的 50\% ${ }^{[1]}$, 其中内陆湖泊系统大于 $0.65 \mathrm{Pg}$ $\mathrm{C} / \mathrm{a}^{[2]}$ (全球海洋约 40 50 Pg C/a), 因而它们被认为是湖泊生态系统中最主要的初级生产者, 在水生植被分 布较少的深水湖泊中或更甚. 湖泊浮游植物初级生产力及其时空异质性的研究已备受国内外学者关注 ${ }^{[3-7]}$, 但我国目前的研究主要集中于长江中下游湖泊或水库 ${ }^{[5-7]}$. 云南高原是我国天然湖泊的主要分布区域之一, 由于国家、地方及公众的关注,该区域湖泊水生态环境方面的研究已越来越受重视;其中,在浮游植物的研 究方面,已有较多关于时空分布与种群动态 ${ }^{[8-9]}$ 、群落演替 ${ }^{[10-11]}$ 、历史演变 ${ }^{[12-13]}$ 及水华控制 ${ }^{[14]}$ 等方面的报 道, 而关于浮游植物初级生产力的研究仍较为零星一一黎尚豪先生等 ${ }^{[15]}$ 于 $1950 \mathrm{~s}$ 利用黑白瓶法开展过一些 先期调查, 珠江水系调查队等单位的调查也涉及到云贵高原湖库的初级生产力 ${ }^{[16]}$, 庄建山 ${ }^{[17]}$ 于 $2002-2003$ 年利用黑白瓶法测定过滇池的浮游植物初级生产力, 申岑等 ${ }^{[18]}$ 于 2006 年 7 月利用黑白瓶法测定过拉市海 3 个点位的浮游植物初级生产力. 程海是典型的封闭型深水湖, 湖泊面积和蓄水量均列云南省九大高原湖泊 第四位, 其不仅是云南省特色生物产业发展基地、世界 3 大螺旋藻养殖基地之一, 还是云南省尚存少量土著 鱼类的重要湖泊 ${ }^{[19]}$. 然而, 关于程海浮游植物初级生产力的研究十分有限, 已有的研究主要是基于沉积物 纪录的结果间接反映该湖初级生产力在历史上有过若干次上升 ${ }^{[20-22]}$, 而缺乏基于原位观测或模型估算的研 究,对其时空分布规律知之甚少.

关于浮游植物初级生产力的估算方法主要包括基于现场测定的黑白瓶法、同位素法和苂光法 ${ }^{[23]}$ 、基于 经验模型的估算法 ${ }^{[24-25]}$ 、基于生物光学模型的 (遥感) 估算法 ${ }^{[26]}$ 和基于黑白瓶法原理的自动监测法 ${ }^{[27]}$ 等. 其中, 黑白瓶法是最传统的测定方法, 具有成本低、结果精确等优势, 但测定费时费力且离散的 (单点位) 数 据并不能很好地代表全湖的状况, 而基于生物光学模型的估算法的最大优势即在于其可应用于时空尺度的 研究, 如最具代表性的生产力垂向归纳模型 (vertically generalized production model, VGPM) ${ }^{[26]}$ 已广泛应用于 国内外水域初级生产力的估算 ${ }^{[5,28]}$. 因此, 本研究基于 2016 年 4 月- 2017 年 2 月在程海开展的现场调查, 在 利用黑白瓶法对单个点位水柱初级生产力及垂直分布进行实测的基础上,通过 VGPM 模型比对并估算探讨 全湖浮游植物初级生产力的时空分布及其影响因子.

\section{1 材料与方法}

\section{1 研究区域概况}

程海 ( $26^{\circ} 27^{\prime} \sim 26^{\circ} 38^{\prime} \mathrm{N}, 100^{\circ} 38^{\prime} \sim 100^{\circ} 41^{\prime} \mathrm{E}$; 图 1) 地处云南省丽江市永胜县中部、金沙江干热河谷地带, 属亚热带季风气候,约 1690 年前后开始演变为内陆封闭型深水湖泊; 程海水面高程 $1501.0 \mathrm{~m}$, 面积 74.6 $\mathrm{km}^{2}$, 平均水深 $25.7 \mathrm{~m}$, 最大水深 $35 \mathrm{~m}$, 蓄水量 $19.8 \times 10^{8} \mathrm{~m}^{3}$, 流域面积 $318 \mathrm{~km}^{2}$; 程海湖床倾斜度大, 约 $87 \%$ 的水面水深大于 $20 \mathrm{~m}$, 是一个典型的中营养深水湖泊 ${ }^{[19]}$.

\section{2 样品采集与指标测定}

2016 年 4 月- 2017 年 2 月,利用黑白瓶法开展码头点位水柱 $24 \mathrm{~h}$ 初级生产力及有关理化指标的逐月 
观测; 同时, 针对码头点位和全湖其他 9 个点位 (图 1) 开展逐月调查, 获取基于 VGPM 估算初级生产力所需 的参数和其他水体理化指标. 除码头点位外, 本研究中的 9 个调查点位及所涉及的真光层深度 $\left(Z_{\mathrm{eu}}\right)$ 及水下 $0.5 \mathrm{~m}$ 处的水温 (WT)、叶绿素 a (Chl.a)、总氮 (TN)、总溶解性氮 (TDN)、总磷 (TP) 和总溶解性磷 (TDP) 浓 度均来源于已发表的同期调查结果 ${ }^{[29]}$, 且码头点位的 $Z_{\mathrm{en}}$ 及水体理化指标的测定方法与之相同; 鉴于各点位 在 2016 年 3 月均无实测 $Z_{\mathrm{eu}}$ 数据, 同时为了使全湖调查与码头点位实测初级生产力的时间段相匹配, 本研究 选取的时间段为 2016 年 4 月- 2017 年 2 月. 为便于探讨浮游植物初级生产力的水平空间异质性, 将全湖分 为南北向的北部湖区 $\left(1^{\#} 、 2^{\#} 、 3^{\#}\right.$ 点 $) 、$ 中部湖区 $\left(4^{\#} 、 5^{\#} 、 6^{\#}\right.$ 点 $)$ 和南部湖区 $\left(7^{\#} 、 8^{\#} 、 9^{\#}\right.$ 点 $)$, 东西向的东部湖区 $\left(3^{\#} 、 6^{\#} 、 9^{\#}\right.$ 点 $) 、$ 中部湖区 $\left(2^{\#} 、 5^{\#} 、 8^{\#}\right.$ 点 $)$ 和西部湖区 $\left(1^{\#} 、 4^{\#} 、 7^{\#}\right.$ 点 $)$.

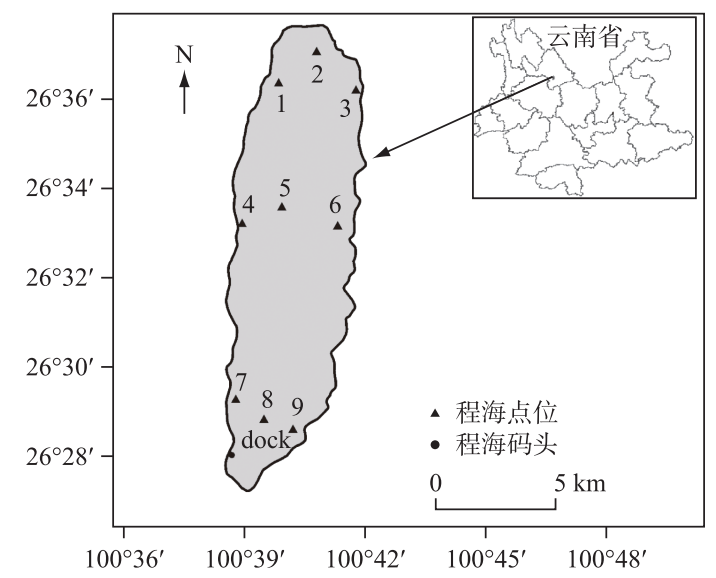

图 1 程海地理位置与采样点位

Fig.1 Location of Lake Chenghai and sampling sites

\section{3 基于黑白瓶法的初级生产力测定}

用采水器分别采取码头点位水体表面 $(0 \mathrm{~m})$ 和水下 $0.5 、 1.0 、 2.0 、 3.0 \mathrm{~m}$ 处 (未达热力分层期的温跃层) 水样, 由瓶底 (各瓶容量为 $250 \mathrm{ml}$ ) 开始分别注满 (溢出 3 倍体积) 1 个初始瓶、2 个黑瓶、2 个白瓶; 初始瓶于 现场固定、充分摇匀后根据碘量法测定初始溶解氧 (DO) 浓度, 黑瓶和白瓶分别悬挂于对应取水水深 $24 \mathrm{~h}$ 后 取出, 现场固定、充分摇匀后根据碘量法测定各瓶的 DO 浓度, DO 的现场固定、测定及各水层总初级生产力 $(\mathrm{GPP})$ 、净初级生产力 $(\mathrm{NPP}) 、$ 呼吸消耗量 $(\mathrm{R})$ 的计算参照文献 $[30]$. 各水层单位生物量的 GPP、NPP 和 R 为各水层 GPP、NPP、R 的值除以对应水层的 Chl.a 浓度; 水柱初级生产力的计算公式 ${ }^{[30]}$ 为:

$$
P_{t}=\sum_{i=1}^{n-1} \frac{P_{i}+P_{i+1}}{2}\left(D_{i+1}-D_{i}\right)
$$

式中, $P_{t}$ 为水柱初级生产力 $\left(\mathrm{g} \mathrm{O}_{2} /\left(\mathrm{m}^{2} \cdot \mathrm{d}\right)\right), P_{i}$ 为第 $i$ 层的初级生产力 $\left(\mathrm{g} \mathrm{O}_{2} /\left(\mathrm{m}^{2} \cdot \mathrm{d}\right)\right), D_{i}$ 为第 $i$ 层的深度 $(\mathrm{m}), n$ 为取样层次数 $(1 \leqslant i \leqslant n-1)$. 本文以 $\mathrm{GPP}_{\mathrm{C}} 、 \mathrm{NPP}_{\mathrm{C}} 、 \mathrm{R}_{\mathrm{C}}$ 分别表征 $0 \sim 3 \mathrm{~m}$ 水柱的总初级生产力、净初级 生产力和呼吸消耗量.

\section{4 基于 VGPM 的初级生产力估算}

经简化的基于 VGPM 估算的真光层总初级生产力 $\left(P P_{\mathrm{eu}}, \mathrm{mg} \mathrm{C} / \mathrm{m}^{2}\right)$ 的公式 ${ }^{[26]}$ 为:

$$
P P_{\text {eu }}=0.66125 P_{\text {opt }}^{B} \cdot \frac{E_{0}}{E_{0}+4.1} \cdot Z_{\text {eu }} \cdot C_{\text {opt }} \cdot D_{\text {irr }}
$$

式中, $E_{0}$ 为水表日 PAR 强度 $\left(\mathrm{mol}\right.$ quanta $\left./ \mathrm{m}^{2}\right), Z_{\mathrm{eu}}$ 为真光层深度 $(\mathrm{m}), C_{\mathrm{opt}}$ 为最大光合速率所在深度的 Chl. a $\left(\mathrm{mg} \mathrm{Chl.a} / \mathrm{m}^{3}\right), D_{\mathrm{irr}}$ 为昼长 $(\mathrm{h}) ; P_{\mathrm{opt}}^{B}$ 为最大光合速率 $(\mathrm{mg} \mathrm{C} /(\mathrm{mg} \mathrm{Chl} \cdot \mathrm{a} \cdot \mathrm{h}))$, 可通过公式 $(3)$ 计算得出 (适用 温度为 $\left.-1 \sim 29^{\circ} \mathrm{C}\right)^{[26]}$ :

$$
P_{\text {opt }}^{B}=1.2596+2.749 \times 10^{-1} W T+6.17 \times 10^{-2} W T^{2}-2.05 \times 10^{-2} W T^{3}+2.46 \times 10^{-3} W T^{4}-
$$




$$
1.348 \times 10^{-4} W T^{5}+3.4132 \times 10^{-6} W T^{6}-3.27 \times 10^{-8} W T^{7}
$$

本研究中, 调查当日的总辐射来源于中国气象数据网 (http://data.cma.cn/) 丽江站(台站编号:56651), 用以代表程海地区的总辐射 ${ }^{[31]}, E_{0}$ 为总辐射的换算值 ${ }^{[32]} ; Z_{\text {eu }}$ 来源于同步调查数据的拟合值; $C_{\mathrm{opt}}$ 以水下 0.5 $\mathrm{m}$ 的 Chl. a 浓度代替; $D_{\text {irr }}$ 以程海镇当日的昼长表征, 来源于便民查询网 (https://richurimo.51240.com/); WT 来源于多参数水质监测仪的同步记录 (水下 $0.5 \mathrm{~m}$ ), 为规避少部分 WT 数据缺失 (全湖 9 个点位 11 个月共 缺失 7 个数据, 其中 5 月 1 个、 6 月 3 个、 10 月 1 个、 11 月 1 个、 12 月 1 个) 及在一定程度上避免其日变化的 影响, 全湖 9 个点位各月的 WT 均以当月各点位的均值代表.

\section{5 统计分析}

本研究中, “全年”指 2016 年 4 月－2017 年 2 月共 11 个月, “春夏季”指 2016 年 4-8 月, “秋冬季” 指 2016 年 9 月 -2017 年 2 月, “均值”指平均值土标准误. 采用两独立样本 (Mann-Whitney U)、多独立样本非参 数检验 (Kruskal-Wallis 1-way ANOVA, Stepwise step-down) 分析有关参数在不同时空条件下的差异; 采用一元 线性回归分析码头点位 $\mathrm{GPP}_{\mathrm{C}}$ 和 $P P_{\mathrm{eu}}$ 的关系; 将 $P P_{\mathrm{eu}}$ 和有关环境因子标准化后, 用一元线性回归和多元逐步 回归分析 $P P_{\mathrm{eu}}$ 和环境因子的关系; 以上分析均使用 SPSS Statistics 24.0 完成, $P<0.05$ 表示显著、 $P<0.01$ 表示 极显著.

\section{2 结果}

\section{1 码头点位初级生产力的垂直分布}

春夏季, GPP (图 $2 \mathrm{a}$ ) 和 $\mathrm{NPP}$ (图 $2 \mathrm{~b}$ ) 均随深度增加而逐渐减小, $3.0 \mathrm{~m}$ 处的值分别为 $0.61 \pm 0.34$ 和 $-0.35 \pm$ $0.67 \mathrm{mg} \mathrm{O} /(\mathrm{L} \cdot \mathrm{d})$; 秋冬季, $0.5 \mathrm{~m}$ 处的 $\operatorname{GPP}(3.16 \pm 0.60 \mathrm{mg} \mathrm{O} /(\mathrm{L} \cdot \mathrm{d}))$ 和 $\mathrm{NPP}(2.04 \pm 0.38 \mathrm{mg} \mathrm{O} /(\mathrm{L} \cdot \mathrm{d}))$ 均 最大, 随后随深度增加逐渐减小, $3.0 \mathrm{~m}$ 处的 $\mathrm{GPP}(0.47 \pm 0.08 \mathrm{mg} \mathrm{O} /(\mathrm{L} \cdot \mathrm{d}))$ 和 $\mathrm{NPP}\left(-0.30 \pm 0.22 \mathrm{mg} \mathrm{O}_{2} /(\mathrm{L} \cdot\right.$ d) ) 均显著小于其他水层 $(P<0.05)$; 全年, GPP 和 NPP 均随深度增加而逐渐减小, $3.0 \mathrm{~m}$ 处的 $\operatorname{GPP}(0.53 \pm$ $0.15 \mathrm{mg} \mathrm{O} /(\mathrm{L} \cdot \mathrm{d}))$ 和 $\mathrm{NPP}(-0.32 \pm 0.31 \mathrm{mg} \mathrm{O} /(\mathrm{L} \cdot \mathrm{d}))$ 均显著小于其他水层 $(P<0.05)$. 对于 $\mathrm{R}$ (图 $2 \mathrm{c}$ ), 其 在春夏季、秋冬季和全年的垂直变化均不明显、各水层间均无显著性差异 $(P>0.05) . \mathrm{GPP} / \mathrm{Chl} . \mathrm{a}($ 图 $2 \mathrm{~d})$ 在 $0.5 \mathrm{~m}$ 处最大, 春夏季、秋冬季和全年的值分别为 $0.058 \pm 0.013 、 0.065 \pm 0.005$ 和 $0.062 \pm 0.006 \mathrm{mg} \mathrm{O}_{2} /$ $(\mu \mathrm{g}$ Chl. $\mathrm{a} \cdot \mathrm{d})$, 随后随深度增加逐渐减小, 至 $3.0 \mathrm{~m}$ 处的值分别为 $0.013 \pm 0.007 、 0.013 \pm 0.004$ 和 $0.013 \pm 0.003$ $\mathrm{mg} \mathrm{O} /(\mu \mathrm{g} \mathrm{Chl} . \mathrm{a} \cdot \mathrm{d}) . \mathrm{NPP} / \mathrm{Chl} . \mathrm{a}$ (图 2e) 在 $0.5 \mathrm{~m}$ 处最大, 春夏季、秋冬季和全年的值分别为 $0.033 \pm 0.011$ 、 $0.043 \pm 0.006$ 和 $0.039 \pm 0.006 \mathrm{mg} \mathrm{O} /(\mu \mathrm{g} \mathrm{Chl} . \mathrm{a} \cdot \mathrm{d})$, 随后随深度增加逐渐减小, 至 $3.0 \mathrm{~m}$ 处的值分别为 $-0.002 \pm$ $0.013 、-0.003 \pm 0.007$ 和 $-0.002 \pm 0.006 \mathrm{mg} \mathrm{O} /(\mu \mathrm{g} \mathrm{Chl.a} \cdot \mathrm{d}) . \mathrm{R} / \mathrm{Chl} . \mathrm{a}($ 图 2f) 的垂直变化不明显、各水层间均 无显著性差异 $(P>0.05)$.

就水柱 $(0 \sim 3.0 \mathrm{~m})$ 初级生产力而言, 码头点位的年均 $\mathrm{GPP}_{\mathrm{C}} 、 \mathrm{NPP}_{\mathrm{C}} 、 \mathrm{R}_{\mathrm{C}}$ 和 $P P_{\mathrm{eu}}$ 分别为 $5.40 \times 10^{3} \pm 0.64 \times 10^{3}$ $\mathrm{mg} \mathrm{O} \mathrm{O}_{2} /\left(\mathrm{m}^{2} \cdot \mathrm{d}\right)\left(2.32 \times 10^{3} \sim 9.40 \times 10^{3} \mathrm{mg} \mathrm{O}_{2} /\left(\mathrm{m}^{2} \cdot \mathrm{d}\right)\right) 、 2.36 \times 10^{3} \pm 0.63 \times 10^{3} \mathrm{mg} \mathrm{O}_{2} /\left(\mathrm{m}^{2} \cdot \mathrm{d}\right)\left(-2.80 \times 10^{3} \sim 4.62 \times\right.$ $\left.10^{3} \mathrm{mg} \mathrm{O} \mathrm{O}_{2} /\left(\mathrm{m}^{2} \cdot \mathrm{d}\right)\right) 、 3.06 \times 10^{3} \pm 0.82 \times 10^{3} \mathrm{mg} \mathrm{O}_{2} /\left(\mathrm{m}^{2} \cdot \mathrm{d}\right)\left(0.08 \times 10^{3} \sim 9.85 \times 10^{3} \mathrm{mg} \mathrm{O} /\left(\mathrm{m}^{2} \cdot \mathrm{d}\right)\right)$ 和 $5.99 \times 10^{3} \pm$ $0.70 \times 10^{3} \mathrm{mg} \mathrm{C} /\left(\mathrm{m}^{2} \cdot \mathrm{d}\right)\left(2.54 \times 10^{3} \sim 11.01 \times 10^{3} \mathrm{mg} \mathrm{C} /\left(\mathrm{m}^{2} \cdot \mathrm{d}\right)\right)$, 春夏季与秋冬季的 $\mathrm{GPP}_{\mathrm{C}} 、 \mathrm{NPP}_{\mathrm{C}} 、 \mathrm{R}_{\mathrm{C}}$ 和 $P P_{\mathrm{eu}}$ 均 无显著性差异 $(P>0.05)$. 除 7 月的 $\mathrm{GPP}_{\mathrm{C}} / \mathrm{R}_{\mathrm{C}}$ 小于 $1 、 \mathrm{NPP}_{\mathrm{C}}$ 为负值外, 其余月份的水柱 $\mathrm{GPP}_{\mathrm{C}} / \mathrm{R}_{\mathrm{C}}$ 均大于 1 、 $\mathrm{NPP}_{\mathrm{C}}$ 均为正值 (图 3).

\section{2 基于 VGPM 估算的全湖 $P P_{\text {eu }}$ 时空分布}

鉴于黑白瓶法难以及时有效地获取全湖多点位初级生产力信息, 且码头点位基于黑白瓶法估算的水柱 $\mathrm{GPP}_{\mathrm{C}}$ 与基于 $\mathrm{VGPM}$ 估算的 $P P_{\mathrm{eu}}$ 有良好的线性关系 $\left(\ln \left(\mathrm{GPP}_{\mathrm{C}}\right)=0.824 \ln \left(P P_{\mathrm{eu}}\right)+0.190, R^{2}=0.597, P<0.01\right.$, $N=11$ ), 本研究以基于 VGPM 估算的 $P P_{\mathrm{eu}}$ 为初级生产力参数开展全湖的时空特征分析.

在时间变化方面 (图 4a), 全年 $P P_{\mathrm{eu}}$ 范围为 $2.74 \times 10^{3} \sim 18.62 \times 10^{3} \mathrm{mg} \mathrm{C} /\left(\mathrm{m}^{2} \cdot \mathrm{d}\right.$ ), 中位数为 $5.94 \times 10^{3} \mathrm{mg}$ $\mathrm{C} /\left(\mathrm{m}^{2} \cdot \mathrm{d}\right)$, 均值为 $6.54 \times 10^{3} \pm 0.30 \times 10^{3} \mathrm{mg} \mathrm{C} /\left(\mathrm{m}^{2} \cdot \mathrm{d}\right)$; 春夏季均值为 $7.17 \times 10^{3} \pm 0.59 \times 10^{3} \mathrm{mg} \mathrm{C} /\left(\mathrm{m}{ }^{2} \cdot \mathrm{d}\right)$, 秋 冬季均值为 $6.05 \times 10^{3} \pm 0.24 \times 10^{3} \mathrm{mg} \mathrm{C} /\left(\mathrm{m}^{2} \cdot \mathrm{d}\right)$, 春夏季与秋冬季的无显著性差异 $(P>0.05) .4-8$ 月期间, $P P_{\mathrm{eu}}$ 随时间推移呈明显的上升趋势, 月最小值、月中位数、月最大值、月均值分别由 4 月的 $2.74 \times 10^{3} 、 2.96 \times$ $10^{3} 、 3.38 \times 10^{3}$ 和 $3.00 \times 10^{3} \pm 0.08 \times 10^{3} \mathrm{mg} \mathrm{C} /\left(\mathrm{m}^{2} \cdot \mathrm{d}\right)$ 逐渐上升至 8 月的 $7.72 \times 10^{3} 、 12.34 \times 10^{3} 、 18.62 \times 10^{3}$ 和 
$11.94 \times 10^{3} \pm 1.22 \times 10^{3} \mathrm{mg} \mathrm{C} /\left(\mathrm{m}^{2} \cdot \mathrm{d}\right) .9$ 月一次年 2 月期间, $9-11$ 月的 $P P_{\mathrm{eu}}$ 总体变化趋势相对稳定, 在 12 月 达到本阶段峰值 $\left(8.53 \times 10^{3} \pm 0.35 \times 10^{3} \mathrm{mg} \mathrm{C} /\left(\mathrm{m}^{2} \cdot \mathrm{d}\right)\right)$ 后逐渐下降至 2 月的 $4.46 \pm 0.19 \times 10^{3} \mathrm{mg} \mathrm{C} /\left(\mathrm{m}^{2} \cdot \mathrm{d}\right), 12$ 月的 $P P_{\mathrm{eu}}$ 显著大于其他月份 $(P<0.05)$.

在空间变化方面, 不论春夏季、秋冬季还是全年, 南中北、东中西的 $P P_{\mathrm{eu}}$ 均无显著性差异 $(P>0.05)$. 就空 间分布的逐月变化而言 (图 5), 若以东西向划分, 11 个月的 $P P_{\mathrm{eu}}$ 均无显著性差异 $(P>0.05)$; 若以南北向划 分, 仅 7 月和 8 月检测出了显著性差异. 7 月, 北部的 $P P_{\mathrm{eu}}\left(11.14 \times 10^{3} \pm 1.05 \times 10^{3} \mathrm{mg} \mathrm{C} /\left(\mathrm{m}^{2} \cdot \mathrm{d}\right)\right)$ 显著高于中 部 $\left(6.96 \times 10^{3} \pm 1.00 \times 10^{3} \mathrm{mg} \mathrm{C} /\left(\mathrm{m}^{2} \cdot \mathrm{d}\right)\right)$ 和南部 $\left(8.55 \times 10^{3} \pm 0.61 \times 10^{3} \mathrm{mg} \mathrm{C} /\left(\mathrm{m}^{2} \cdot \mathrm{d}\right)\right)(P<0.05)$, 南部略高于中 部; 8 月, 南、中、北部的 $P P_{\mathrm{eu}}$ 分别为 $14.04 \times 10^{3} \pm 0.33 \times 10^{3} 、 8.89 \times 10^{3} \pm 0.62 \times 10^{3}$ 和 $12.90 \times 10^{3} \pm 3.16 \times 10^{3} \mathrm{mg} \mathrm{C} /$ $\left(\mathrm{m}^{2} \cdot \mathrm{d}\right)$, 南部显著高于中部 $(P<0.05)$, 北部略高于中部但不显著 $(P>0.05)$.
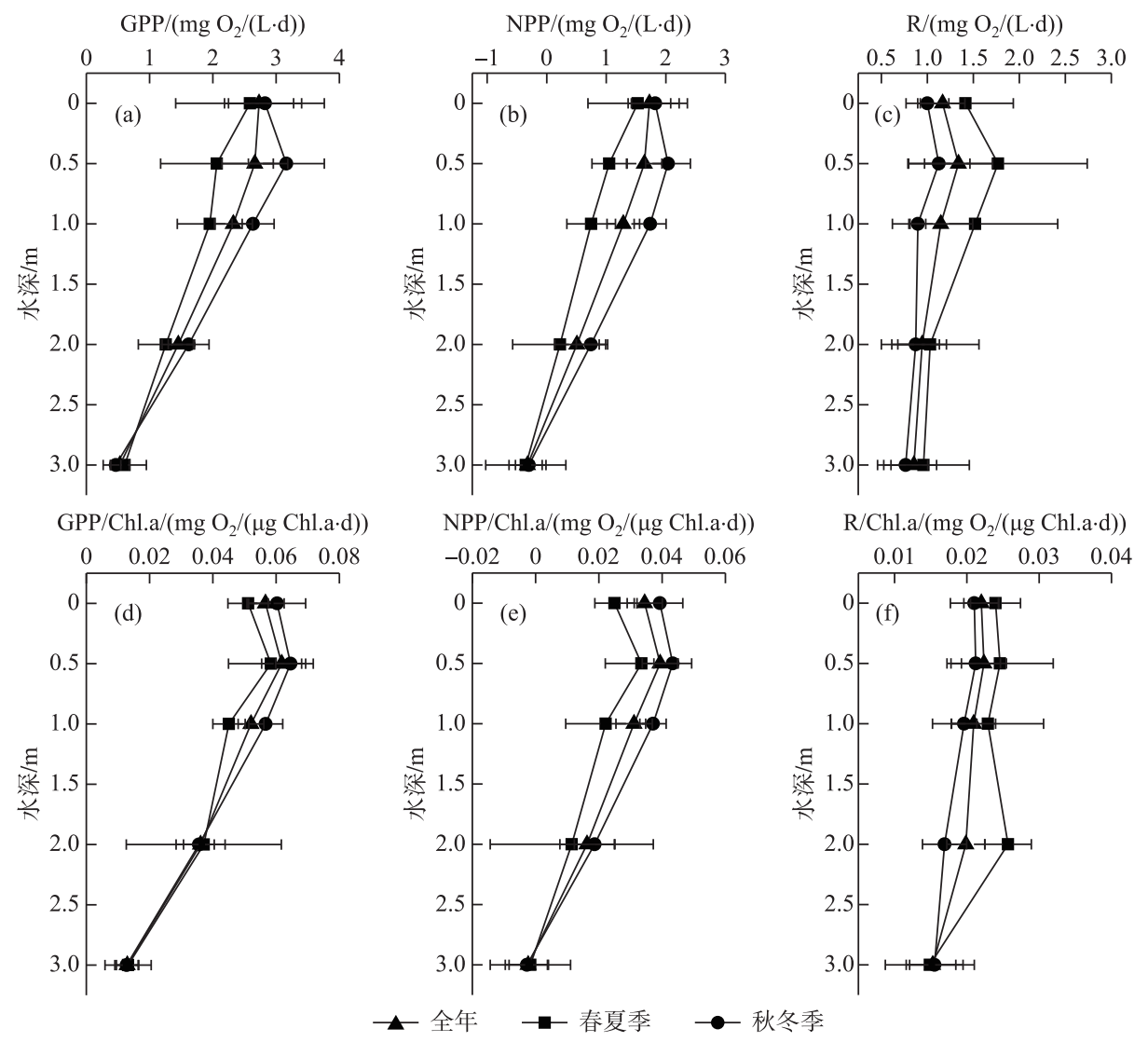

图 2 程海码头点位不同水层 $\operatorname{GPP}(\mathrm{a}) 、 \mathrm{NPP}(\mathrm{b})$ 和 $\mathrm{R}(\mathrm{c})$ 及单位叶绿素 $\operatorname{GPP}(\mathrm{d}) 、 \mathrm{NPP}(\mathrm{e})$ 和 $\mathrm{R}(\mathrm{f})$ 的垂直分布 (图中数据为平均值士标准误差)

Fig.2 Vertical porfile of GPP (a), NPP (b), R (c) and GPP/Chl.a (d), NPP/Chl.a (e), $\mathrm{R} / \mathrm{Chl} . \mathrm{a}(\mathrm{f})$ at the dock of Lake Chenghai

\section{3 全湖理化指标变化及其与 $P P_{\mathrm{eu}}$ 的关系}

程海全湖 Chl.a 、 $Z_{\mathrm{eu}} 、$ WT、TN、TP、TDN 和 TDP 各指标的年均值 (范围) 分别为 $35.72 \pm 2.09 \mu \mathrm{g} / \mathrm{L}(9.46 \sim$ $112.87 \mu \mathrm{g} / \mathrm{L}) 、 4.64 \pm 0.13 \mathrm{~m}(2.71 \sim 10.71 \mathrm{~m}) 、 20.66 \pm 0.39^{\circ} \mathrm{C}\left(14.57 \sim 25.79^{\circ} \mathrm{C}\right) 、 0.90 \pm 0.02 \mathrm{mg} / \mathrm{L}(0.65 \sim 1.67 \mathrm{mg} /$ L) $、 0.053 \pm 0.001 \mathrm{mg} / \mathrm{L}(0.024 \sim 0.084 \mathrm{mg} / \mathrm{L}) 、 0.68 \pm 0.01 \mathrm{mg} / \mathrm{L}(0.41 \sim 0.96 \mathrm{mg} / \mathrm{L})$ 和 $0.016 \pm 0.001 \mathrm{mg} / \mathrm{L}(0.003 \sim$ $0.045 \mathrm{mg} / \mathrm{L}$ ) (图 $4 \mathrm{~b} \sim \mathrm{h}$ ). 季节变化方面, 春夏季的 $Z_{\mathrm{eu}} 、 \mathrm{TP} 、 \mathrm{TDP}$ 显著高于秋冬季 $(P<0.01)$, 春夏季的 TDN 显著 低于秋冬季 $(P<0.01)$, 春夏季和秋冬季的 Chl.a、WT 与 TN 均无显著性差异 $(P>0.05)$. 实验期间春夏季的 Daily $Q$ 与秋冬季的无显著性差异 $(P>0.05)$, 春夏季的当日 $\operatorname{Dirr}$ 显著大于秋冬季 $(P<0.01)$ (图 $3 \mathrm{~b})$. 


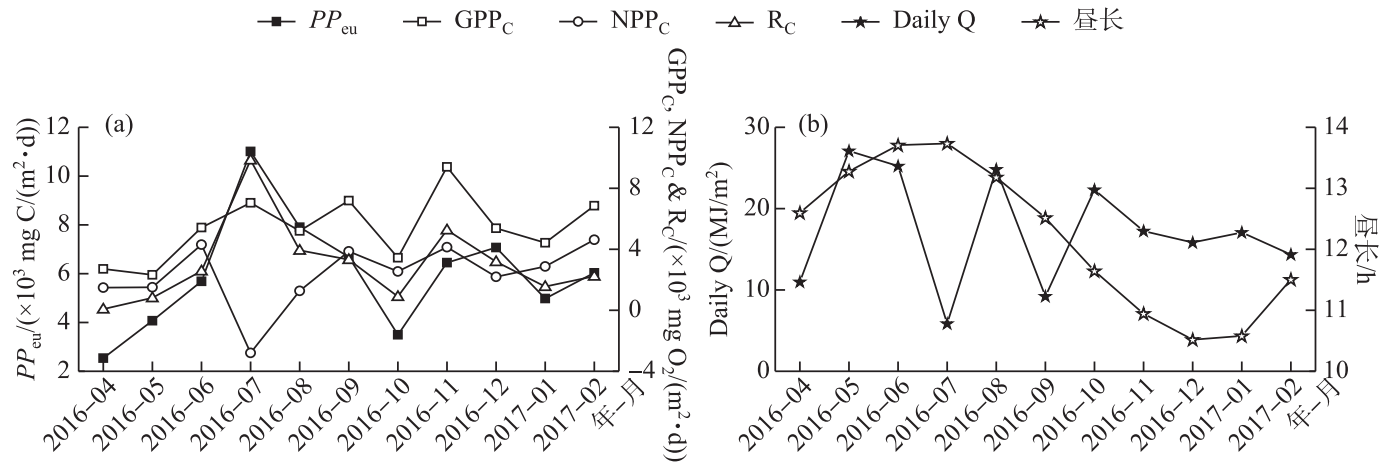

图 3 程海码头点位基于黑白瓶法估算的水柱 $\mathrm{GPP}_{\mathrm{C}} 、 N P P_{\mathrm{C}} 、 \mathrm{R}_{\mathrm{C}}$ 和

基于 VGPM 估算的 $P P_{\mathrm{eu}}$ 逐月变化 (a) 和实验期间当日总辐射 (Daily Q) 与昼长的逐月变化 (b)

Fig.3 Monthly variation of $\mathrm{GPP}_{\mathrm{C}}, \mathrm{NPP}_{\mathrm{C}}$ and $\mathrm{R}_{\mathrm{C}}$ estimated by light-dark bottle method and $P P_{\text {eu }}$ estimated by VGPM at the dock (a), and daily total radiation (Daily Q) and day length during experimental period (b) at the dock of Lake Chenghai
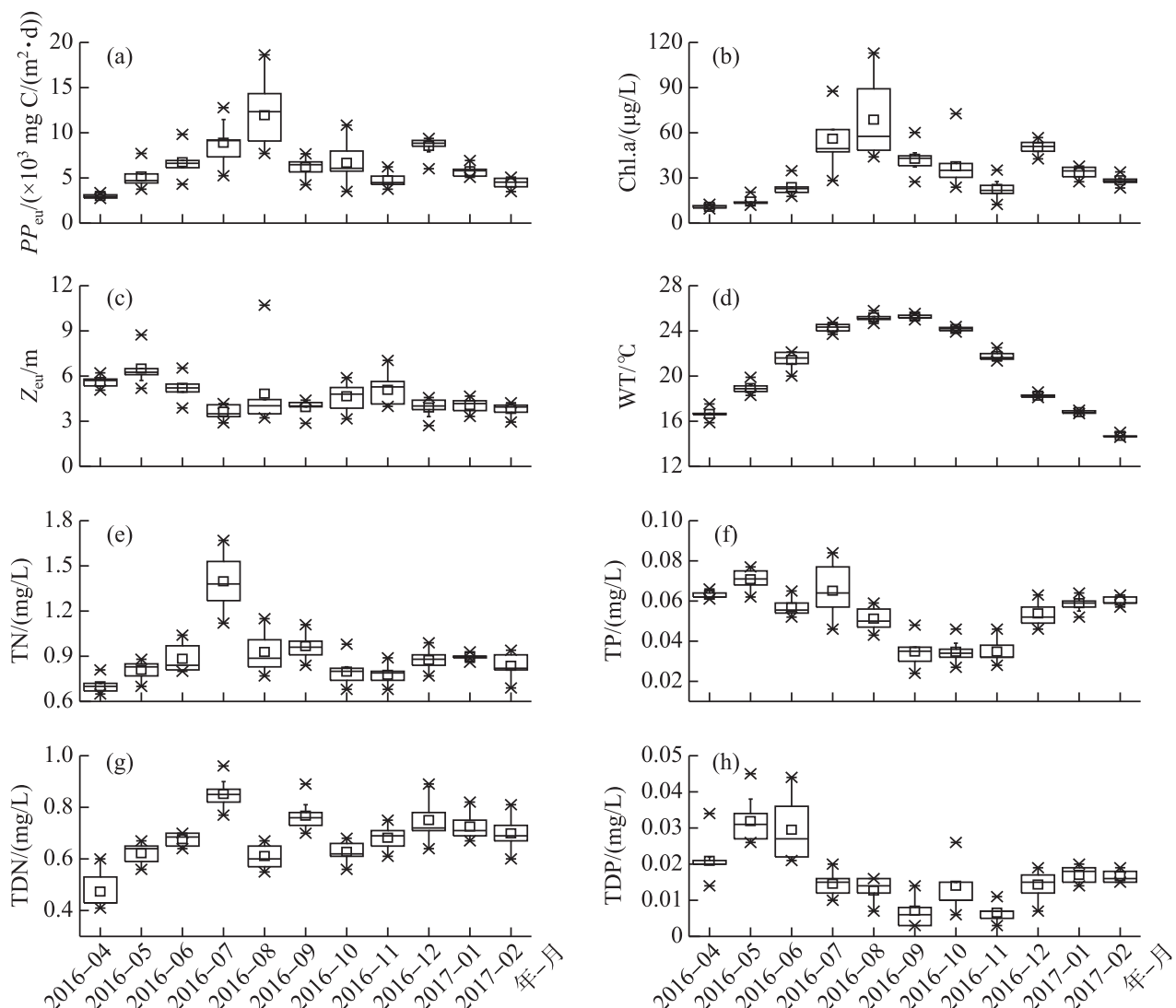

图 4 程海全湖 $P P_{\text {eu }}(\mathrm{a}) 、 \mathrm{Chl} . \mathrm{a}(\mathrm{b}) 、 Z_{\mathrm{eu}}(\mathrm{c}) 、 \mathrm{WT}(\mathrm{d}) 、 \mathrm{TN}(\mathrm{e}) 、 \mathrm{TP}(\mathrm{f}) 、 \mathrm{TDN}(\mathrm{g})$ 和 $\mathrm{TDP}(\mathrm{h})$ 的逐月变化

Fig.4 Monthly variations of $P P_{\text {eu }}($ a $)$, Chl.a (b), $Z_{\text {eu }}(\mathrm{c})$, WT (d), TN (e), TP (f), TDN (g) and TDP (h) of Lake Chenghai 




图 5 程海全湖 $P P_{\mathrm{eu}}$ 空间分布的逐月变化

Fig.5 Spatial distribution of $P P_{\text {eu }}$ in Lake Chenghai at different months

为了检验 $P P_{\mathrm{eu}}$ 的主要影响因子, 将 $P P_{\mathrm{eu}}$ 及有关参数标准化后以 $Z$ score $\left(P P_{\mathrm{eu}}\right)$ 为因变量、其他参数的标 准化得分为自变量开展一元线性回归和多元逐步回归, 结果如图 6 和表 1 所示. 全年来看, $P P_{\mathrm{eu}}$ 与 Chl.a、 WT、TN、TDN 有显著的正向关系, Chl. a 是最重要的因子; 春夏季, $P P_{\mathrm{eu}}$ 与 Chl. a、WT、TN、TDN 有显著的正向 关系, 与 TDP 有显著的负向关系, WT 和 Chl. a 是较重要的因子; 秋冬季, $P P_{\mathrm{eu}}$ 与 Chl. $\mathrm{a} 、 \mathrm{TN}$ 有显著的正向关 系, Chl.a 是最重要的因子. 此外,春夏季、秋冬季和全年的全湖月均 $P P_{\mathrm{eu}}$ 与 Daily Q、Dirr 均无显著的线性回 归关系 $(P>0.05)$.

\section{3 讨论}

针对程海码头点位的逐月调查中, 仅 7 月的水柱 $\mathrm{GPP}_{\mathrm{C}} / \mathrm{R}_{\mathrm{C}}$ 小于 1 、水柱 $\mathrm{NPP}_{\mathrm{C}}$ 为负值, 就浮游植物初级生 产力而言, 说明此处总体上属于自养型. 7 月, 码头点位水体表面和水下 $0.5 、 1.0 、 2.0 、 3.0 \mathrm{~m}$ 处的 NPP 分别为 $3.15 、 1.86 、-0.52 、-2.68$ 和 $-2.89 \mathrm{mg} \mathrm{O}_{2} /(\mathrm{L} \cdot \mathrm{d}), \mathrm{NPP}_{\mathrm{C}}$ 为负值与 $1 \mathrm{~m}$ 及以下水深 $\mathrm{NPP}$ 的抵消作用有关; 7 月实 验期间的日总辐射仅为 $5.86 \mathrm{MJ} / \mathrm{m}^{2}$, 是各月实验当日的最低值, 加之较低的真光层深度而不利于水柱尤其 下层的光合作用,较高的水温 (水下 $0.5 \mathrm{~m}$ 处为 $24.97^{\circ} \mathrm{C}$ ) 和浮游植物生物量 (水体表面和水下 $0.5 、 1.0 、 2.0$ 、 $3.0 \mathrm{~m}$ 的 Chl.a 浓度分别为 $88.13 、 93.52 、 102.16 、 96.19$ 和 $86.05 \mu \mathrm{g} / \mathrm{L}$, 均为码头点位各月的最大值) 则利于增 加呼吸消耗量. 类似地, 安徽太平湖水库的研究结果亦显示其 7 月的 $\mathrm{R}_{\mathrm{C}}$ 最高、 $\mathrm{NPP}_{\mathrm{C}}$ 为负值 ${ }^{[6]}$. 



图 6 Zscore $\left(P P_{\text {eu }}\right)$ 与 Zscore $\left(\right.$ Chl.a)、Zscore $\left(Z_{\mathrm{eu}}\right) 、 Z$ score $(\mathrm{WT}) 、 Z s c o r e(T N) 、$ Zscore (TP)、Zscore (TDN) 和 Zscore (TDP) 的一元线性回归 (仅展示有统计学显著关系的结果)

Fig.6 Unary linear regression between $Z$ score $\left(P P_{\text {eu }}\right)$ and Zscore (Chl.a), Zscore $\left(Z_{\text {eu }}\right)$, Zscore( WT), Zscore( TN), Zscore( TP), Zscore(TDN), Zscore( TDP) (only the results with significant statistical relationship were displayed)

鉴于码头点位黑白瓶法测定初级生产力的深度范围均处于混合层, 水温、营养盐等因子垂直分布的差异 较小, 故浮游植物同化速率的垂直分布或更受制于光照条件. 过高的光强会抑制浮游植物的同化速率 ${ }^{[33]}$, 进而 降低水柱表层的初级生产力 ${ }^{[34]}$. 类似地, 本研究中不论春夏季、秋冬季或全年, GPP/Chl.a、NPP/Chl.a 的最大 值均出现在次表层即水下 $0.5 \mathrm{~m}$ 处, 而后随深度增加而减小. GPP、NPP 不仅与浮游植物的同化速率有关, 还与 生物量有关,其最高值一般出现在水体表层或次表层 ${ }^{[6,35]}$, 本研究中的 GPP 和 NPP 亦呈现出了类似的特征. 
$R 、 R / C h l . a$ 均无明显的垂直分布差异, 或是因为呼吸消耗量及速率主要受制于(生物量和) 水温.

一般而言, 同一水体的浮游植物初级生产力均会具有一定程度的季节或水平分布异质性. 本研究中, 虽 然程海的 $P P_{\mathrm{eu}}$ 并未表现出春夏季和秋冬季的显著差异, 但仍有明显的月份间的异质性; 虽然程海 $P P_{\mathrm{eu}}$ 整体 的空间异质性较弱,但在特殊月份 (7 月和 8 月) 表现出了明显的空间异质性. 程海 $P P_{\mathrm{eu}}$ 的时空分布特征与 该湖相对独特的生境条件有关. 浮游植物初级生产力主要受制于光照 ${ }^{[33]}$ 、温度 ${ }^{[36]}$ 、氮磷营养盐 ${ }^{\left[{ }^{[36-37]}\right.}$ 和浮游 植物生物量的综合影响. 程海地处金沙江干热河谷区, 辐射条件整体充分, 本研究并未检出 Daily Q 和 Dirr 对全湖月均 $P P_{\mathrm{eu}}$ 的显著影响; $\mathrm{Ma}$ 等 ${ }^{[38]}$ 的研究显示当温度 $\geqslant 12.5^{\circ} \mathrm{C}$ 时太湖冬季的微囊藻能继续生长, 本研究 的全年最低表层水温仍达 $14.57^{\circ} \mathrm{C}$, 且码头点位的实测结果亦显示程海的辐射和水温不太可能因过低而限 制浮游植物的初级生产过程; 同时, 通过一元线性回归和多元逐步回归发现, 程海 $P P_{\mathrm{eu}}$ 的全年变化主要受制 于 Chl.a、WT、TN 和 TDN, 而春夏季与秋冬季的 Chl.a、WT 和 TN 并无显著性差异, 虽然秋冬季的 TDN 显著高 于春夏季, 但秋冬季的 Dirr 显著低于春夏季, 故而春夏季与秋冬季的 $P P_{\mathrm{eu}}$ 并未表现出显著性差异. 将春夏季 和秋冬季的 $P P_{\mathrm{eu}}$ 分别来看: 春夏季, $P P_{\mathrm{eu}}$ 总体随 Chl.a、WT、TN 和 TDN 的升高而升高, 而 $P P_{\mathrm{eu}}$ 与 TDP 的负向 关系可能是由于浮游植物光合作用与生长过程吸收消耗了水体的溶解态磷; 秋冬季, 虽然 Dirr 和 WT 均呈 下降趋势, 但期间 $P P_{\mathrm{eu}}$ 的主要影响因子 Chl.a 和 TN 并未随时间推移而呈明显的下降趋势, 故而 $P P_{\mathrm{eu}}$ 并未出 现明显的下降, 且在 12 月出现了新的峰值, 该峰值的出现或与热分层消退期间的表层营养盐补充及生物量 增加有关. 空间分布方面, 我们的同步研究表明, 程海 $Z_{\mathrm{eu}}$ 和 Chl. a 浓度的空间异质性较弱 ${ }^{[29]}$; 类似地, 本研 究春夏季、秋冬季和全年的 WT、TN、TDN、TP、TDP 在南中北部间或东中西部间均无明显的空间异质性 $(P>$ 0.05 ). 据测算, 程海流域南岸的人湖 TDN 和 TDP 负荷分别占了全流域的 $49.51 \%$ 和 $50.16 \%$, 北岸的人湖 TDN 和 TDP 负荷分别占了全流域的 $23.40 \%$ 和 $24.01 \%$, 而东岸和西岸的人湖 TDN 和 TDP 所占比例均不足 $14 \%{ }^{[39]}$. $7 、 8$ 月是程海降水量最充沛的两个月份, 分别占全年总降水量的 $26.71 \%$ 和 $22.98 \%$; 降雨可使大量 陆域营养盐输人, 进而使南北部的 $P P_{\mathrm{eu}}$ 要高于中部, 7 月北部的 $P P_{\mathrm{eu}}$ 高于南部或与主导风向 (南风) 引起的 风生流及其他可能的水动力条件的间接作用有关.

表 $1 Z \operatorname{zscore}\left(P P_{\text {eu }}\right)$ 与 Zscore ( Chl.a)、Zscore $\left(Z_{\text {eu }}\right) 、 Z s c o r e(W T) 、 Z s c o r e(T N) 、$ Zscore (TP)、Zscore (TDN) 和 Zscore (TDP) 的多元逐步回归 *

Tab.1 Multiple stepwise regression between $Z$ score $\left(P P_{\text {eu }}\right)$ and Zscore( Chl.a), Zscore $\left(Z_{\text {eu }}\right)$, Zscore (WT), Zscore( TN), Zscore(TP), Zscore(TDN), Zscore( TDP)

\begin{tabular}{|c|c|c|c|c|c|c|}
\hline 时间 & 多元逐步回归公式 & $R_{\text {adj }}^{2}$ & $F$ & $P$ & VIF & $\mathrm{d} f$ \\
\hline \multirow[t]{3}{*}{ 全年 } & $\operatorname{Zscore}\left(P P_{\mathrm{eu}}\right)=0.816 \mathrm{Zscore}(\mathrm{Chl} . \mathrm{a})$ & 0.657 & 177.236 & $<10^{-21}$ & 1.000 & 92 \\
\hline & $\operatorname{Zscore}\left(P P_{\text {eu }}\right)=1.12 \operatorname{Zscore}($ Chl.a $)+0.602 \operatorname{Zscore}\left(Z_{\text {eu }}\right)$ & 0.916 & 505.513 & $<10^{-47}$ & 1.355 & 92 \\
\hline & $\begin{aligned} \operatorname{Zscore}\left(P P_{\text {eu }}\right)= & 1.092 \operatorname{Zscore}(\text { Chl.a })+0.651 \operatorname{Zscore}\left(Z_{\text {eu }}\right) \\
& +0.137 \text { Zscore }(\text { TDN })\end{aligned}$ & 0.931 & 412.809 & $<10^{-50}$ & $1.297 \sim 1.512$ & 92 \\
\hline \multirow[t]{3}{*}{ 春夏季 } & $\operatorname{Zscore}\left(P P_{\text {eu }}\right)=1.21 \mathrm{Zscore}(\mathrm{WT})$ & 0.675 & 86.088 & $<10^{-9}$ & 1.000 & 41 \\
\hline & $\operatorname{Zscore}\left(P P_{\text {eu }}\right)=1.352 \operatorname{Zscore}(\mathrm{WT})+0.295 \operatorname{Zscore}\left(Z_{\text {eu }}\right)$ & 0.740 & 59.211 & $<10^{-10}$ & 1.136 & 41 \\
\hline & $\begin{aligned} \operatorname{Zscore}\left(P P_{\text {eu }}\right)= & 0.49 \mathrm{Zscore}(\mathrm{WT})+0.578 \mathrm{Zscore}\left(Z_{\mathrm{eu}}\right) \\
& +0.84 \mathrm{Zscore}(\text { Chl.a })\end{aligned}$ & 0.950 & 263.389 & $<10^{-23}$ & $1.49 \sim 3.625$ & 41 \\
\hline \multirow[t]{3}{*}{ 秋冬季 } & Zscore $\left(P P_{\text {eu }}\right)=0.881$ Zscore $($ Chl.a $)$ & 0.631 & 88.217 & $<10^{-10}$ & 1.000 & 51 \\
\hline & $\operatorname{Zscore}\left(P P_{\text {eu }}\right)=1.117$ Zscore $($ Chl.a $)+0.543 \operatorname{Zscore}\left(Z_{\text {eu }}\right)$ & 0.934 & 359.835 & $<10^{-28}$ & 1.154 & 51 \\
\hline & $\begin{aligned} \operatorname{Zscore}\left(P P_{\text {eu }}\right)= & 1.192 \mathrm{Zscore}(\text { Chl.a })+0.617 \operatorname{Zscore}\left(Z_{\text {eu }}\right) \\
& -0.109 \mathrm{Zscore}(\mathrm{WT})\end{aligned}$ & 0.962 & 431.337 & $<10^{-32}$ & $1.251 \sim 1.383$ & 51 \\
\hline
\end{tabular}

* Zscore 为标准化得分, 用 Exclude cases listwise 方法处理缺失值; VIF 为方差膨胀因子.

程海是一个典型的深水湖泊, 沉积物纪录的历史显示该湖的初级生产力有过若干次升高 ${ }^{[20-22]}$; 然而, 程 海的水生植物已呈衰退趋势 ${ }^{[40]}$, 意味着浮游植物对初级生产力的相对贡献将进一步上升, 尤其在蓝澡逐渐 成为浮游植物优势类群后 ${ }^{[41]}$, 浮游植物初级生产力的升高或已成为富营养化进程加快的一个表象. 近十多 年来, 程海水环境质量指数下降 ${ }^{[42]}$, 以氮磷浓度升高和透明度下降等为代表的富营养化进程加剧 ${ }^{[43]}$, 加之 
流域社会经济快速发展 ${ }^{[42]}$ 、有关污染治理并未有效跟进 ${ }^{[44]}$ 以及流域土地利用与气候变化等因素 ${ }^{[45]}$, 或将 直接或间接地对程海的浮游植物生物量和初级生产力产生重要影响. 从本研究获取的有限数据来看, 浮游 植物生物量是程海全年和秋冬季 $P P_{\mathrm{eu}}$ 变化最重要的影响因子, 春夏季则需重点关注水温和浮游植物生物量 的共同影响; 同时, 营养盐亦需被关注, 如春夏季、秋冬季和全年的 TN, 春夏季和全年的 TDN, 而春夏季 TDP 的补充供给很可能使浮游植物初级生产力大幅提高. 需要指出的是, 单位生物量的浮游植物初级生产力并 不一定随营养盐的升高而升高, 过高的营养水平下由于光辐射不足等可能产生限制作用 ${ }^{[46]}$; 同时, 当营养盐 相对富足时, 浮游植物生物量亦可能受制于光照、温度、风速等物理条件 ${ }^{[9,47]}$, 而过高的生物量亦不利于浮游 植物物种多样性的维持 ${ }^{[48]}$. 就程海而言, 虽然该湖仍处于中营养水平, 但鉴于其仍将面临富营养化进程加 快和藻类水华暴发的现实背景, 不论是基于浮游植物初级生产力保障的角度, 还是基于藻类水华防治和浮 游植物物种多样性维持的角度,均需关注对湖泊营养水平的控制.

鉴于浮游植物生物量是程海浮游植物初级生产力的重要影响因子, 有必要开展关于浮游植物生物量及 其影响因子的进一步分析, 已由另文报道 ${ }^{[29]}$. 此外, 由于光合速率除温度外还易受光照、营养盐甚至浮游植 物自身及其他可能的生物因子影响, 今后的研究仍需结合程海实际的浮游植物群落及其生境条件对最佳光 合速率等参数进行修正, 亦需借助遥感等技术手段, 旨在更准确地估算程海的浮游植物初级生产力、更全面 地了解其时空分布规律,并进一步为程海的保护和渔业发展提供支撑.

\section{4 结论}

程海码头点位 $\mathrm{GPP}_{\mathrm{C}} 、 \mathrm{NPP}_{\mathrm{C}}$ 和 $\mathrm{R}_{\mathrm{C}}$ 的年均值分别为 $5.40 \times 10^{3} \pm 0.64 \times 10^{3} 、 2.36 \times 10^{3} \pm 0.63 \times 10^{3}$ 和 $3.06 \times 10^{3} \pm$ $0.82 \times 10^{3} \mathrm{mg} \mathrm{O} \mathrm{O}_{2} /\left(\mathrm{m}^{2} \cdot \mathrm{d}\right)$, 说明总体上为自养型; 垂直分布方面, 不论春夏季、秋冬季或全年, GPP、NPP、 $\mathrm{GPP} / \mathrm{Chl} . \mathrm{a}$ 和 NPP/Chl. $\mathrm{a}$ 的最大值均出现在表层 (水体表面) 或次表层 (水下 $0.5 \mathrm{~m}$ ), 而后随深度的增加而 减小, 其中 NPP 和 NPP/Chl.a 至水下 $3.0 \mathrm{~m}$ 处的均值已小于 $0, \mathrm{R}$ 和 $\mathrm{R} / \mathrm{Chl}$. a 则无明显差异. 全湖 $P P_{\mathrm{eu}}$ 的时 空变化方面, 春夏季是 $P P_{\mathrm{eu}}$ 快速上升的时节, 秋冬季 $P P_{\mathrm{eu}}$ 的月变化呈波动状态, 春夏季和秋冬季的总体分布 无显著性差异, 这与该湖相对独特的生境条件及其变化有关; $P P_{\mathrm{eu}}$ 整体的空间异质性较弱,但在降水最为充 沛的 7、8 月表现出了南北向的空间异质性, 这与流域营养盐输人异质性和降水条件有关. $P P_{\text {en }}$ 的主要影响因 子具有季节异质性: 全年, 主要受Chl.a、WT、TN 和 TDN 的影响, Chl.a 是最重要的因子; 春夏季, 主要受Chl.a、 WT、TN、TDN 和 TDP 的影响, WT 和 Chl. a 是较重要的因子; 秋冬季, 主要受 Chl. a 和 TN 的影响, Chl. a 是最重 要的因子. 此外, 浮游植物对程海初级生产力的贡献可能会进一步上升, 基于浮游植物初级生产力保障、藻 类水华防治和物种多样性维持的角度,均需关注对程海营养水平的控制.

致谢: 王俊松、李杰、宋迪、郑超群和朱春锡等协助了野外调查或指标分析工作,特此感谢!

\section{5 参考文献}

[ 1 ] Behrenfeld MJ, O'Malley RT, Siegel DA et al. Climate-driven trends in contemporary ocean productivity. Nature, 2006, 44(7120): 752-755. DOI: $10.1038 /$ nature05317.

[ 2 ] Tranvik LJ, Downing JA, Cotner JB et al. Lakes and reservoirs as regulators of carbon cycling and climate. Limnology and Oceanography, 2009, 54(6_part_2) : 2298-2314. DOI: 10.4319/lo.2009.54.6_part_2.2298.

[ 3 ] Fahnenstiel GL, Sayers MJ, Shuchman RA et al. Lake-wide phytoplankton production and abundance in the Upper Great Lakes: 2010-2013. Journal of Great Lakes Research, 2016, 2(3) : 619-629. DOI: 10.1016/j.jglr.2016.02.004.

[ 4 ] Darchambeau F, Sarmento H, Descy JP. Primary production in a tropical large lake: The role of phytoplankton composition. Science of the Total Environment, 2014, 473/474: 178-188. DOI: 10.1016/j.scitotenv.2013.12.036.

[ 5 ] Li YH, Ge G, Wang ML et al. Characteristics of primary productivity of Lake Poyang in wet and dry seasons and the correlations with environmental factors using the Vertically Generalized Production Model. J Lake Sci, 2016, 28(3) : 575-582. DOI: 10.18307/2016.0313. [李艳红, 葛刚, 王茂林等. 垂向归纳模型下鄱阳湖丰、枯水期初级生产力特征及与环 境因子相关性分析. 湖泊科学, 2016, 28(3): 575-582.]

[ 6 ] Feng SM, Liu DY, Li DJ et al. Analysis on the temporal and spatial distribution of the primary productivity and its influencing factors in Lake Taiping (Reservoir), Anhui Province. J Lake Sci, 2016, 28(6) : 1361-1370. DOI: 10.18307/2016. 
0622. [冯世敏, 刘冬燕, 李东京等. 安徽太平湖水库初级生产力时空分布及分析. 湖泊科学, 2016, 28(6): 1361-1370. ]

[ 7 ] Xiong Q, Huang LC, Ye SW et al. The seasonal variations and spatial distribution of the primary productivities of phytoplankton in the Three Gorges Reservoir. Acta Hydrobiologica Sinica, 2015, 39(5) : 853-860. DOI: 10.7541/2015.113. [ 熊倩, 黄立成, 叶少文等. 三峡水库浮游植物初级生产力的季节变化与空间分布. 水生生物学报, 2015, 39(5): 853-860.]

[ 8 ] Wang S, Zhu L, Li Q et al. Distribution and population dynamics of potential anatoxin-a-producing cyanobacteria in Lake Dianchi, China. Harmful Algae, 2015, 8: 63-68. DOI: 10.1016/j.hal.2015.07.005.

[ 9 ] Zhang M, Yu Y, Yang Z et al. The distribution of phytoplankton along trophic gradients and its mediation by available light in the pelagic zone of large eutrophic lakes. Canadian Journal of Fisheries and Aquatic Sciences, 2012, 69(12): 1935-1946. DOI: 10.1139/f2012-113.

[10] Wu Y, Li L, Zheng L et al. Patterns of succession between bloom-forming cyanobacteria Aphanizomenon flos-aquae and Microcystis and related environmental factors in large, shallow Dianchi Lake, China. Hydrobiologia, 2016, 765(1): 1-13. DOI: $10.1007 / \mathrm{s} 10750-015-2392-0$.

[11] Cao J, Hou Z, Li Z et al. Succession of phytoplankton functional groups and their driving factors in a subtropical plateau lake. Science of the Total Environment, 2018, 631/632: 1127-1137. DOI: 10.1016/j.scitotenv.2018.03.026.

[12] Dong J, Zhou Q, Gao Y et al. Long-term effects of temperature and nutrient concentrations on the phytoplankton biomass in three lakes with differing trophic statuses on the Yungui Plateau, China. Annales de Limnologie - International Journal of Limnology, 2018, 54: 9. DOI: 10.1051/limn/2017031.

[13] Zhou Q, Zhang Y, Lin D et al. The relationships of meteorological factors and nutrient levels with phytoplankton biomass in a shallow eutrophic lake dominated by cyanobacteria, Lake Dianchi from 1991 to 2013. Environmental Science and Pollution Research, 2016, 23(15) : 15616-15626. DOI: 10.1007/s11356-016-6748-4.

[14] Zhou Q, Li L, Huang L et al. Combining hydrogen peroxide addition with sunlight regulation to control algal blooms. Environmental Science and Pollution Research, 2018, 25(3) : 2239-2247. DOI: 10.1007/s11356-017-0659-x.

[15] Li SH, Yu MJ, Li GZ et al. Limnological survey of the lakes of Yunnan Plateau. Oceanologia et Limnologic Sinica, 1963, 5(2) : 87-114. [ 黎尚豪, 俞敏娟, 李光正等. 云南高原湖泊调查. 海洋与湖沼, 1963, 5(2) : 87-114.]

[16] He ZH. Primary production and energy exchange efficiency of the lakes and reservoirs in China. Fisheries Science, 1987, 6 (1) : 24-30. [何志辉. 中国湖泊水库的初级生产力及其能量转化效率. 水产科学, 1987, 6(1): 24-30.]

[17] Zhuang JS. Study on the primary production and the influence factors in demonstration area to control cyanobacterial bloom of Dianchi Lake during 2002-2003 [Dissertation]. Shanghai: Shanghai Normal University, 2004. [庄建山. 滇池控制水 华示范区 (2002-2003) 初级生产及其影响因素 [学位论文]. 上海: 上海海洋大学, 2004.]

[18] Shen C, Jiao YC, Bai YQ et al. Plankton community characteristics in Lake Lashi, and estimation on its primary productivity and fish productivity. Journal of Yunnan Normal University: Natural Sciences Edition, 2012, 32(4) : 52-59. [申岑, 焦媛春, 白岩青等. 拉市海浮游生物群落特征及其初级生产力和鱼产力的估算. 云南师范大学学报: 自然科学版, $2012,32(4): 52-59$.]

[19] Dong YX, Zhao L, Chen YH et al. Succession of nine plateau lakes and regulation of ecological safety in Yunnan Province. Ecological Economy, 2015, 31(1): 185-191. [董云仙, 赵否, 陈异晖等. 云南九大高原湖泊的演变与生态安全调 控. 生态经济, 2015, 31(1): 185-191.]

[20] Wan GJ, Chen JA, Xu SQ et al. Indication of ${ }^{210} \mathrm{~Pb}_{\mathrm{ex}}$ deposition flux sudden increases to lake primary production-take Chenghai as example. Science in China: Ser D: Earth Sciences, 2004, 34(2): 154-162. [万国江, 陈敬安, 胥思勤等. ${ }^{210} \mathrm{~PB}_{\mathrm{ex}}$ 沉积通量突发增大对湖泊生产力的指示一一程海为例. 中国科学: D 辑: 地球科学, 2004, 34(2): 154-162. ]

[21] Wu JL, Wang SM. Carbon and oxygen stable isotope tracer in eutrophication process of Chenghai, Yunnan. Quaternary Sciences, 2003, 23(5) : 557-564. [ 吴敬禄, 王苏民. 云南程海富营养化过程的碳氧稳定同位素示踪. 第四纪研究, $2003,23(5): 557-564$. $]$

[22] Wu JL, Jiang XZ, Xia WL et al. Climate and primary productivity over the last 500 years of the Chenghai Lake, Yunnan. Marine Geology \& Quaternary Geology, 2002, 22(2) : 95-98. [ 吴敬禄, 蒋雪中, 夏威岗等. 云南程海近 500 年来湖泊 初始生产力的演化. 海洋地质与第四纪地质, 2002, 22(2) : 95-98.] 
[23] Melrose DC, Oviatt CA, O'Reilly JE et al. Comparisons of fast repetition rate fluorescence estimated primary production and ${ }^{14} \mathrm{C}$ uptake by phytoplankton. Marine Ecology-Progress Series, 2006, 311: 37-46. DOI: 10.3354/meps311037.

[24] Zhang YL, Qin BQ, Chen WM et al. Chlorophyll a content and primary productivity of phytoplankton in Meiliang Bay of Taihu Lake. Chinese Journal of Applied Ecology, 2004, 15(11): 2127-2131. [张运林, 秦伯强, 陈伟民等. 太湖梅梁 湾浮游植物叶绿素 $\mathrm{a}$ 和初级生产力. 应用生态学报, 2004, 15(11) : 2127-2131.]

[25] Cox TJS, Maris T, Soetaert K et al. Estimating primary production from oxygen time series: A novel approach in the frequency domain. Limnology and Oceanography: Methods, 2015, 13(10) : 529-552. DOI: 10.1002/lom3.10046.

[26] Behrenfeld MJ, Falkowski PG. Photosynthetic rates derived from satellite-based chlorophyll concentration. Limnology and Oceanography, 1997, 2(1) : 1-20. DOI: 10.4319/lo.1997.42.1.0001.

[27] Collins JR, Fucile PD, McDonald G et al. An autonomous, in situ light-dark bottle device for determining community respiration and net community production. Limnology and Oceanography: Methods, 2018, 16(6) : 323-338. DOI: 10.1002/ lom3.10247.

[28] Behrenfeld MJ, Randerson JT, McClain CR et al. Biospheric primary production during an ENSO transition. Science, 2001, 291(5513) : 2594-2597. DOI: 10.1126/science.1055071.

[29] Li KD, Zhou YY, Zhou QC et al. Temporal-spatial distribution of euphotic depth and its influencing factors in Lake Chenghai, Yunnan Province, China. J Lake Sci, 2019, 31(1) : 256-267. DOI: 10.18307/2019.0124. [李凯迪, 周远洋, 周 起超等. 云南程海真光层深度的时空分布及其影响因子. 湖泊科学, 2019, 31(1) : 256-267.]

[30 ] Editorial Board of "Water and Wastewater Monitoring and Analysis Methods" of the Ministry of Environmental Protection of the People's Republic of China. Water and wastewater monitoring and analysis methods: 4th edition. Beijing: China Environmental Science Press, 2002 [国家环境保护总局《水和废水监测分析方法》编委会. 水和废水监测分析方法: 第 4 版. 北京: 中国环境科学出版社, 2002]

[31] Wang XF, Zhu Y, Fan LZ et al. Spatial-temporal variations of solar global radiation in Yunnan Province during 19612007. Advances in Climate Change Research, 2009, 5(1) : 29-34. [王学锋, 朱勇, 范立张等. 1961-2007 年云南太阳 总辐射时空变化特征. 气候变化研究进展, 2009, 5 (1) : 29-34.]

[32] Zhang GQ, Zhu JJ, Li RP et al. Estimation of photosynthetically active radiation (PAR) using sunshine duration. Chinese Journal of Ecology, 2015, 34(12) : 3560-3567. DOI: 10.13292/j.1000-4890.2015.0335. [张广奇, 朱教君, 李荣平 等. 基于日照时数的光合有效辐射 (PAR) 时数估算方法. 生态学杂志, 2015, 34(12) : 3560-3567.]

[33] Torremorell A, Llames ME, PÉRez GL et al. Annual patterns of phytoplankton density and primary production in a large, shallow lake: The central role of light. Freshwater Biology, 2009, 54(3) : 437-449. DOI: 10.1111/j.1365-2427.2008. 02119.x.

[34] Zhang YL, Qin BQ, Chen WM et al. Phytoplankton primary production in spring Meiliang Bay, Lake Taihu. J Lake Sci, 2005, 17 (1) : 81-86. DOI: 10.18307/2005.0113. [张运林, 秦伯强, 陈伟民等. 太湖梅梁湾春季浮游植物初级生产 力. 湖泊科学, $2005, \mathbf{1 7}(1): 81-86$. ]

[35] Zhang Q, Yuan YJ, Mi WJ et al. Primary production and its influencing factors in Xiangxi River, Three-Gorges Reservoir. J Lake Sci, 2015, 27(3) : 436-444. DOI: 10.18307/2015.0310. [张琪, 袁轶君, 米武娟等. 三峡水库香溪河初级生 产力及其影响因素分析. 湖泊科学, 2015, 27(3): 436-444.]

[36] Tadonléke R. Evidence of warming effects on phytoplankton productivity rates and their dependence on eutrophication status. Limnology and Oceanography, 2010, 55(3) : 973-982. DOI: 10.4319/lo.2010.55.3.0973.

[37] Lyngsgaard MM, Markager S, Richardson K. Changes in the vertical distribution of primary production in response to landbased nitrogen loading. Limnology and Oceanography, 2014, 59(5) : 1679-1690. DOI: 10.4319/lo.2014.59.5.1679.

[38] Ma J, Qin B, Paerl HW et al. The persistence of cyanobacterial (Microcystis spp.) blooms throughout winter in Lake Taihu, China. Limnology and Oceanography, 2016, 61(2) : 711-722. DOI: 10.1002/lno.10246.

[39] Chen XK, Liu XB, Peng WQ et al. Estimation of control strategies for pollution loads from non-point sources in the Chenghai watershed. Environmental Science, 2018, 39(1): 77-88. DOI: 10.13227/j.hjkx.201705061. [陈学凯, 刘晓波, 彭 文启等. 程海流域非点源污染负荷估算及其控制对策. 环境科学, 2018, 39(1): 77-88.]

[40] Dong YX, Tan ZW, Wang JS. Current status and evolution trend of aquatic vegetation in Chenghai Lake. Plant Diversity and Resources, 2011, 33(4): 451-457. DOI: 10.3724/SP.J.1143.2011.11027. [董云仙, 谭志卫, 王俊松. 程海水生 植被现状及其演变趋势. 植物分类与资源学报, 2011, 33(4) : 451-457.] 
[41] Dong YX, Tan ZW, Zhu X et al. Annual variation of phytoplankton community structure and change of the number in Chenghai Lake. Ecology and Environmental Sciences, 2012, 21(7): 1289-1295. [董云仙, 谭志卫, 朱翔等. 程海藻类 植物种群结构和数量的周年变化特征. 生态环境学报, 2012, 21(7): 1289-1295.]

[42] Yang SM, Wang T, Wang ZP et al. Research of water ecological capacity variation in Lake Chenghai, Yunnan, China. Express Water Resources \& Hydropower Information, 2018, 39(2): 39-44. [杨世美, 汪涛, 王泽平等. 程海湖水生态承载 力变化研究. 水利水电快报, 2018, 39(2): 39-44.]

[43] Yang YX. Analysis of eutrophication trend and suggestion of water quality target in recent 10 years in Lake Chenghai. Technology and Economic Guide, 2016, (25): 84-85. [ 杨耀玕. 程海近 10 年富营养化趋势分析及水质目标建议. 科技经 济导刊, 2016, (25): 84-85.]

[44] Dong YX, Zhang XX, Tan ZW et al. Key points and difficulties of water environmental protection and treatment of Chenghai Lake. Environmental Science Survey, 2017, 36(2): 51-59. [董云仙, 张晓旭, 谭志卫等. 程海水环境保护和治理 的重点与难点. 环境科学导刊, 2017, 36(2): 51-59.]

[45] Xiao Q, Yang K, Hong L. Remote sensing monitoring and temporal-spatial analysis of surface water body area changes of lakes on the Yunnan-Guizhou Plateau over the past 30 years. J Lake Sci, 2018, 30(4) : 1083-1096. DOI: 10.18307/ 2018.0421. [肖茜, 杨昆, 洪亮. 近 30a 云贵高原湖泊表面水体面积变化遥感监测与时空分析. 湖泊科学, 2018, 30(4) : 1083-1096.]

[46] Yoshiyama K, Sharp JH. Phytoplankton response to nutrient enrichment in an urbanized estuary: Apparent inhibition of primary production by over eutrophication. Limnology and Oceanography, 2006, 51(1, part 2) : 424-434. DOI: 10.4319/ lo.2006.51.1_part_2.0424.

[47] Qin B, Zhu G, Gao G et al. A drinking water crisis in Lake Taihu, China: Linkage to climatic variability and lake management. Environmental Management, 2010, 5(1) : 105-112. DOI: 10.1007/s00267-009-9393-6.

[48 ] Zhang M, Straile D, Chen F et al. Dynamics and drivers of phytoplankton richness and composition along productivity gradient. Science of the Total Environment, 2018, 625: 275-284. DOI: 10.1016/j.scitotenv.2017.12.288. 